\title{
Firma Performansını Etkileyen Faktörler ve Türkiye Örneği
}

\author{
The Factors Affecting Firm Performance: The Case of Turkey
}

Özge KORKMAZ1', Süleyman Serdar KARACA²

\section{ÖZET}

Bu çalışmada, firma performansını etkileyen faktörler incelenmek istenmiştir. Firma performansının ölçülmesinde hisse senedinin yılsonu kapanış fiyatı ve hisse getiri oranı kullanılmıştır. Hisse senedinin yılsonu kapanış fiyatı ve hisse getiri oranı ile nakit kar payı dağıtım oranı, aktif karlılığı, fiyat/ kazanç oranı, hisse başına kar, net kar büyümesi, piyasa değeri / defter değeri, piyasa değeri ve özsermaye karlılığı değişkenleri arasındaki ilişki incelenmiştir. Çalışmada, IMKB 30 Endeksine dâhil olan 16 şirket 1998-2010 yılları için panel regresyon modeli ile incelenmiștir. Çalışmada iki model oluşturulmuş ve buna göre, Model 1'de hisse kapanış fiyatını, Temettü Ödeme Oranındaki (DPR) ve Hisse Başına Kardaki (EPS) değişimi artıırken, Aktif Karlılığındaki (ROA) değişimin azalttığı ve Piyasa Değeri Defter Değeri (M_B) ve Piyasa Değeri Artışı (MVI) ise Hisse Kapanış Fiyatını (CLS) etkilemediği sonucuna ulaşılmıştır. Model 2'de ise Hisse Getiri Oranını (RSR), Piyasa Değeri Artışı (MVI) ve Hisse Başına Kar (EPS) artıııken, Aktif Karlılığı (ROA) ise etkilemediği gözlenmiş̧ir.

Anahtar Kelimeler: Firma performansı, panel regresyon, hisse kapanış fiyatı, hisse getiri oranı

\section{GiRiş}

Finansal yönetimin temel amacı, firmaların bugünkü değerini hissedarlar açısından maksimum yapmaktır. Bu temel amaca ulaşmak, firmanın mevcut hisse senetlerinin piyasa değerini maksimum kılmakla mümkündür. Firmalar, bu amaca ulaşmak için, piyasa değeri, karlılık, hisse başına kar, fiyat / kazanç oranı vb. oranları yakından takip ederek firmanın piyasa değerini maksimum yapma hedefini gerçekleştirmek isterler. Halka açık, özellikle IMKB'de işlem gören bir firmada, firma değeri, firmanın hisse senetlerinin borsadaki kapanış fiyatı ile toplam hisse senedi sayısının çarpımı sonucu bulunan değerdir. Dolayısı ile kapanış fiyatı, işletmelerin piyasa değerlerinin hesaplanmasında çok önemli bir değişken olup, hisse kapanış fiyatları, kar payı dağıtımında da önemli bir rol oynamaktadır.

\section{ABSTRACT}

In this study, there has been intended to analyze the factors affecting the performance of firms. Year end closing price of stocks and rate of stock return were used to measure performance of the firm. There has been analyzed the relationships between the variables of year-end closing price of the stock, rate of stock return and cash dividend payout ratio, return on assets, price/ earnings ratio, earnings per share, net profit growth, market to book value ratio, market value and return on equity. In the study, there have been analyzed 16 companies included in ISE 30 Index for 1998-2010 years using the panel regression model. There were created two models in the research and according to this, whereas Closing Price of the Stock (CLS) was increased by the change in Dividend Payout Ratio (DPR) and Earnings Per Share (EPS) in Model 1, it increased the change in Return on Assets (ROA) and it did not affect the Market to Book value (M_B) and Market Value Increase (MVI) and Closing Price of Stock (CLS). In Model 2, there has been observed that whereas Market Value Increase (MVI) and Earnings Per Share (EPS) have increased the Rate of Stock Return (RSR), it has not affected Return on Assets (ROA).

Keywords: Firm performance, panel regression, closing price of stock, rate of stock return

Yatırımcılar, bir firmaya yatırım yaparken, finansal oranları göz önüne alarak yatırım yaparlar. Finansal oranlar, firmalara özgü oranlar olduğu için yatırımcılara hisse senetlerinin gerçek değeri hakkında bilgi verebilmektedir. Bu oranlar, likidite, karlılık, faaliyet, mali yapı ve borsa performans (piyasa temelli)oranlarıdır. Hisse senedi getirileri özellikle piyasa derinliği fazla olmayan değişken piyasalarda spekülatif hareketlerden oldukça fazla etkilenebilmektedir. Ayrıca yatırımları sonucunda iki tür kazanç elde ederler. Bunlardan birincisi, kar payı getirisi, diğeri ise sermaye kazancıdır. Bu getiriler, yatırımcıların firmaya yatırım yaparken elde edecekleri getirilerdir. Bu nedenle de yukarıda bahsedilen oranlar firmalar ve firmalara yatırım yapan yatırımcılar açısından oldukça önemlidir. Bu oranlar analiz edilerek, yatırımcılara bir firmaya yatırım kararı alırken ek bilgiler sağlayarak, güvenle yatırım yapmalarına imkân tanır. 
Çalışmanın amacı, Türkiye'de 1998-2010 dönemi için hisse kapanış fiyatı ile hisse getiri oranını etkileyen finansal oranlar tespit edilmesi ve bu oranlar vasıtasıyla firmaların performansının araştırılmasıdır. Çalışmada, ulusal ve uluslararası literatür incelenmiş, daha sonra kullanılan veri seti ve yöntemden bahsedilmiştir. Son olarak da analiz sonucunda elde edilen bulgular değerlendirilmiştir.

\section{LITERATÜR TARAMASI}

Literatürde firmaların performansını ölçen birçok çalışma mevcuttur. Yapılan çalışmalardan bazıları, uygulamaları ve sonuçları ile kısaca aşağıda belirtilmiştir.

Basu (1977) hisse senedine ait yatırım performansının fiyat/kazanç oranı (F/K) ile ilişkisini incelediği çalışmasında, 1956:09-1971:08 dönemini ele almıştır. New York Borsası'nda alım satım işlemi yapılan 1400 sanayi firmasının hisselerini analizinde kullanmıştır. Basu' nun çalışmasında F/K oranı ile ilgili bilgilerin hisse senetleri fiyatlarına, etkin piyasa hipotezinin yarı güçlü formunun gerektirdiği gibi hızlı bir şekilde yansımadığı sonucuna varmıştır. Çünkü ele alınan dönem süresince, düşük $F / K$ oranına sahip portföylerin, yüksek $F / K$ oranına sahip menkul kıymetlere oranla daha yüksek getiri elde ettiklerini belirtmiştir.

Mukherji vd.(1997) çalışmalarında, Kore Borsası'nda hisse senedi getirileri ile köklü değişkenler arasındaki ilişkileri 1982-1993 döneminde incelemişlerdir. Çalışmalarında, yıllık hisse senedi getirileri ile piyasa değeri / defter değeri oranı, satışlar / fiyat oranı ve borç / özsermaye oranları arasında pozitif bir ilişki, firma büyüklüğü değişkeni ile negatif ilişki saptanmıştır. Ayrıca, fiyat / kazanç oranı ve beta katsayısı ile anlamlı ilişkiler bulunamamıştır.

Crowder ve Wohar (1998) çalışmalarında, hisse senedi fiyatı ve kar payı dağıtımı arasındaki uzun dönem ilişkisini bugünkü değer modeli ile incelemişlerdir. Çalışmalarında çeyrek dönemlik hisse senedi fiyatı ile kar payı dağıtımı arasındaki ilişkiyi 1919-1926 dönemleri itibariyle incelemişlerdir. Hisse senedi fiyatı ile kar payı dağıtımı arasında kuvvetli bir ilişki olduğu sonucuna ulaşmışlardır.

Lewellen (2002) çalışmasında, finansal oranların hisse senedi getirisini tahmin etme yeteneği üzerine yeni bir test geliştirmiştir. Çalışmada, 1946-2000 yılları arası veriler kullanılmış olup, 1946-2000 döneminde Kar Payı piyasa getirisini tahmin etmiş, buna karşılık Piyasa Değeri/Defter Değeri ve Fiyat/Kazanç Oranı daha kısa dönemde (1963- 2000), getirileri tahmin edebilmektedir. Canbaş, Düzakın ve Kılıç (2002) çalışmalarında 1993-1997 döneminde IMKB'de işlem gören 173 endüstri şirket işletmesinin hisse senedi getiri tahmininde kullanılan önemli finansal oranların; fiyat/kazanç oranı (F/K), piyasa değeri/defter değeri oranı (PD/DD) ile likidite, kârlılık ve sermaye yapısı oranları olduğunu tespit etmişlerdir. Ayrıca çalışmada, yatırımcı açısından yararlı bilgi sağlayan oranların; likidite, finansal yapı ve kârlılık oranları olduğunu tespit etmişlerdir.

Batchelor ve Orakcıoğlu (2003) ise 1990-1994 döneminde temel olarak hisse ve nakit temettünün hisse fiyatına etkisini araştırmıştır. Bu çalışmada, temettü ödeme günü olay günü olarak alınmış, açıklama günü 4-6 hafta geri gidilerek tahmin edilmiş ve fiyat etkisinin tespitinde olay bağlantılı sabit terimli GARCH süreci yöntemi kullanılmıştır. Çalışmanın sonucunda nakit temettünün açıklanmasının fiyat üzerine etkisi olduğu bulgularına ulaşılamamıştır. Omran ve Ragab (2004), Mısır'da faaliyet gösteren 46 firma için 1996-2000 dönemini dikkate alarak gerçekleştirdikleri çalışmalarında, şirketlerin likidite, varlıkların etkin kullanımı, karlılık, mali yapı ve sabit yükümlülükleri karşılama durumlarını ölçen 10 finansal oran kullanılmıştır. Çalışmalarında kurdukları doğrusal model sonuçlarına göre özsermaye karlılığı ile hisse senedi getirisi arasında önemli bir ilişki bulunmaktadır. Elde edilen analiz sonuçları finansal oranlarla hisse senedi getirileri arasında doğrusal olmayan ilişkilerin var olduğunu göstermekte ve bu ilişkilerin hisse senedi getiri davranışlarının doğrusal ilişkiye göre daha iyi bir şekilde tanımladığını ortaya koymaktadır. Şamiloğlu (2005) İstanbul Menkul Kıymetler Borsası'nda işlem gören deri ve gıda sektöründeki 58 firmanın hisse başına getirileri ile kazançlar, nakit akımları, hisse başına kar ve hisse başına defter değeri arasındaki ilişkiyi 1999-2002 dönemi için çoklu regresyon modeli aracılığı ile incelemiştir. Ayrıca hisse fiyatları ile kazançlar, nakit akımları, hisse başına kar ve hisse başına defter değeri arasındaki ilişkileri yine çoklu regresyon modeli aracılığıyla incelemiştir. Çalışmada kurulan çoklu regresyon modelleri her yıl ve bütün yılların toplamı için ayrı ayrı oluşturulmuş olup, hisse fiyatları ile hisse başına kazanç ve hisse başına defter değeri arasında anlamlı bir ilişki olduğu sonucuna ulaşılmıştır. Hisse senedi getirileri ile nakit akımları, faaliyet kazançları ve yıllık büyüme arasında ise anlamlı bir ilişki olmadığı gözlenmiştir.

Oh, Kim ve Kim (2006), 1981-2000 arası 20 yıllık dönemde Kore Hisse Pazarı'nda işlem gören firmaların yıllık verilerini kullanmışlardır. Firma düzeyinde oluşmuş panel veriler ve finansal analiz sisteminde kullanılan veriler 2002'de Kore Yatırım Hizmeti (KISFAS 2002) ve TS2000 (Korea Listed Companies Asso- 
ciation 2001) tarafından yayınlanan hisse fiyatı verilerinden oluşmuştur. Ayrıca beklenen eğimi oluşturmak için sadece Aralık sonu firma mali yılı ve Mart sonu seçilen hisse fiyatlarından elde edilmiştir. Bu şekilde çalışmalarında 140 firmanın tamamını incelemişlerdir. Çalışma Kore Hisse Pazar verilerini kullanarak hisse fiyatı ve hisse başına kazanç arasındaki ilişkiyi incelemiştir. Durağan olmayan veriler kullanmışlardır. Panele dayanan testler, bireysel hisse fiyatları hisse başına kazançla birleşim sunmazken, hisse fiyatlarının hisse başına kazanç ile birleştiğini ileri sürmüşlerdir. Test sonuçları çok güçlü çıkmıştır. Fiyat/kazanç rasyosunda zayıf ortalamadan sapmayı destekleyen deliller olmasına rağmen, güçlü ortalamadan sapmayı destekleyen karışık deliller bulmuşlardır. Sonuçta hisse fiyatları uzun dönemde ve ortalamada firma temelleri ile hareket ettiği gözlenmiştir. Ege ve Bayrakdaroğlu (2009) 2004 yılında IMKB30 endeksinde işlem gören 18 şirket için, finansal oranlarla hisse senedi getirileri arasındaki ilişki lojistik regresyon analizi ile araştırılmıştır. Değişkenlerin belirlenmesinde Illeriye Doğru Adımsal Ekleme (Forward Stepwise-Wald) yöntemi kullanılmıştır. Yapılan bu çalışmada hisse senedi getirilerini açıklamada Fiyat/Kazanç Oranı(F/K), Nakit Oranı(NO) ve Toplam Varlıkların Devir Hızı Oranı (TVDH) modele eklendiğinde açıklama gücünün arttığı ve dolayısıyla önemli birer bağımsız değişken olduğu görülmüştür. Ancak, tahmini yapılan logit model için PD/DD oranının, önemli bir bağımsız değişken olmadığı sonucuna ulaşılmıştır.

Dehuan ve Jin (2008) çalışmalarında, firmaları seçerken bunların yıllık getiriler açısından piyasada en yüksek \%10'luk performansa sahip olanları analize dâhil etmişlerdir. Çalışmalarında, basit ve çoklu regresyon analizi yapılmış olup, yıllık hisse senedi getirileri bağımlı değişken olarak kullanılmış ve toplam varlık devir hızı, hisse başına kardaki değişim, kar marjı, aktif karlılığı, özsermaye karlılığı ve satışlardaki karlılık ise kullandıkları bağımsız değişkenlerdir. Çalışmalarının sonucu, yukarıda sayılan bağımsız değişkenlerin hisse senedi getirisinde, inceleme döneminin ilk iki yılında anlamlı bir etkiye sahip olduğunu ortaya koymuştur. Bu değişkenler, genellikle hisse senedi fiyatları artarken, açıklama gücünün azaldığı sonucunu göstermektedir. Moderes vd. (2008) çalışmalarında, finansal oranlarla fazla getiri arasındaki ilişkiyi incelemiş ve Tahran Borsası'na kayıtlı 43 firma üzerinde Hisse Senedi Performansını Etkileyen Rasyolar ve IMKB 30 Endeksi'nde incelemelerde bulunmuştur. Mart 2001-Mart 2005 yıllarını belirli dönemlere (Mart 2001-Mart 2002; Mart 2004-Mart 2005 gibi) ayırarak incelemiştir. Aşırı getiri ile finansal oranlar arasındaki ilişkiyi inceledikleri çalışmalarının sonuçları aktif karlılığı, kar marjı, fiyat/kazanç oranları ile finansal oranların anlamlı ilişkide olduğu gözlenmiştir.

Horasan (2009) çalışmasında, 2000-2006 yılları arasında fiyat/kazanç oranının kapanış fiyatları ve gecikmeli getiri üzerine etkisini incelemiştir. Fiyat/kazanç oranı ile gecikmeli kapanış fiyatları arasında istatistiksel olarak anlamlı pozitif ilişki tespit etmiştir. Ayrıca, gecikmeli getiri ve fiyat/kazanç oranı arasındaki ilişkiyi de istatistiksel olarak anlamlı ve negatif olarak bulmuştur. Günalp vd. (2010) çalışmalarında, Türkiye'de nakit temettü kararının hisse senedi getirisini etkileyebilecek nitelikte önemli bir bilgi olduğunu belirtmişlerdir. Çalışma sonucunda ise, nakit temettünün açıklanması sonrasında hisse başına nakit temettü oranı ile kümülatif normalüstü getiri arasında istatistiksel olarak anlamlı bir ilişkinin varlığını ortaya koymuş ve bu ilişkinin negatif yönlü olduğunu tespit etmişlerdir. Buna göre, nakit temettü kararının kamuya açıklanması piyasada olumsuz bir sinyal olarak algılanmakta ve bu nedenle hisse senedi fiyatı düşmektedir. Hisse başına yüksek nakit temettü açıklayan hissenin normalüstü değer kaybı, hisse başına düşük nakit temettü açıklayan hissenin fiyatına göre daha fazladır.

Okafor vd. (2011) çalışmalarında, Nijerya borsasında kar payı dağıtım politikası ile hisse senedi fiyat değişimleri arasındaki ilişkiyi incelemişlerdir. Çalışmalarında, hisse senedi fiyat değişimleri ile temettü verimi ve kar payı dağıtım oranı arasındaki ilişkiyi çoklu regresyon analizi ile incelemişlerdir. Sonuçta, temettü veriminin hisse senedi fiyatı üzerine negatif bir etkiye, kar payı dağıtım oranının ise bazı yıllarda negatif bazı yıllarda ise pozitif bir etkiye sahip olduğunu görmüşlerdir. Kar dağıtım politikasının hisse senedinin fiyatı ile ilgili olduğunu çalışmalarında söylemişlerdir. Khan vd. (2011) kar dağıtım politikasının hisse senedi fiyatını etkileyip etkilemeyeceğini inceledikleri çalışmalarında, temettü verimi, hisse başına kar, öz sermaye karlıı̆̆ı, vergi sonrası kar gibi değişkenlerin hisse senedi fiyatı ile pozitif olarak ilişkili olduğunu, dağıtılmayan karlar oranı ile negatif bir ilişki içinde olduğunu görmüşlerdir.

Habib vd. (2012) çalışmalarında kar payı dağıtım politikası ile hisse senedi fiyatı oynaklığı arasındaki ilişkiyi analiz etmişlerdir. Temettü verimi ve kar payı dağıtım oranıyla hisse senedi fiyatı arasındaki ilişkiyi analiz etmek için yatay kesit regresyon modeli kullanmışlardır. Çalışmalarında, hisse senedi fiyatı ile temettü verimi arasında pozitif bir ilişki, kar payı ödeme oranıyla negatif bir ilişki bulmuşlardır. Literatür çalışmasının özeti Tablo 1'de sunulmuştur. 
Tablo 1: Literatür Özet

\begin{tabular}{|c|c|c|c|c|}
\hline YAZAR & DÖNEM & YÖNTEM & DEĞiSSKENLER & SONUC \\
\hline Basu (1977) & $\begin{array}{l}\text { 1956-1971 } \\
\text { Aylık }\end{array}$ & & $\begin{array}{l}\text { Hisse senedi } \quad \text { yatırım } \\
\text { performansı, Fiyat / Kazanç } \\
\text { oranı }\end{array}$ & $\begin{array}{l}\text { Fiyat / Kazanç oranı ile ilgili } \\
\text { bilgilerin hisse senedi fiyatlarına } \\
\text { hızlı bir şekilde yansımadığını tespit } \\
\text { etmişlerdir. }\end{array}$ \\
\hline $\begin{array}{l}\text { Mukherji vd. } \\
\text { (1997) }\end{array}$ & $\begin{array}{l}1982-1993 \\
\text { yıllık }\end{array}$ & $\begin{array}{l}\text { Spearman } \\
\text { Korelasyon } \\
\text { Katsayısı }\end{array}$ & $\begin{array}{l}\text { Piyasa değeri / defter değeri } \\
\text { (B/M), Borç/öz sermaye (D/E), } \\
\text { Hisse başına kazanç oranı } \\
\text { (E/P), Sermaye piyasa değeri } \\
\text { (MVE), Satı̧lar/hisse başına } \\
\text { satışoranı (D/E) Piyasa Endeksi } \\
\text { (Beta) }\end{array}$ & $\begin{array}{l}\text { Hisse senedi getirisi ile PD/DD, } \\
\text { Satışlar / Fiyat, Borç / Özsermaye } \\
\text { oranları arasında pozitif; frima } \\
\text { büyüklüğü değişkeni ile negatif, } \\
\text { ayrıca F/K oranı ile Beta katsayısı ile } \\
\text { anlamlı ilişkiler bulunamamıştır. }\end{array}$ \\
\hline $\begin{array}{l}\text { Crowder ve } \\
\text { Wohar (1998) }\end{array}$ & $\begin{array}{l}\text { 1919-1926 } \\
\text { Çeyrek } \\
\text { Dönemlik }\end{array}$ & $\begin{array}{l}\text { Bugünkü } \\
\text { Değer Modeli }\end{array}$ & $\begin{array}{l}\text { Hisse Senedi Fiyatı, Kar Payı } \\
\text { Dağıtımı }\end{array}$ & $\begin{array}{l}\text { HSF ile KPD arasında kuvvetli bir } \\
\text { ilişki vardır. }\end{array}$ \\
\hline Lewellen (2002) & $\begin{array}{l}\text { 1946-2000 } \\
\text { Aylık }\end{array}$ & $\begin{array}{l}\text { Regresyon } \\
\text { Analizi }\end{array}$ & $\begin{array}{l}\text { Kar Payı Getirisi, Defter } \\
\text { Değeri/Piyasa Değeri, Fiyat / } \\
\text { Kazanç Oranı, Hisse Senedi } \\
\text { Getirisi }\end{array}$ & $\begin{array}{l}\text { Kar Payı Getirisi uzun dönemde, } \\
\text { Piyasa Değeri /Defter Değeri ile } \\
\text { fiyat / kazanç oranı kısa dönemde } \\
\text { Hisse senedi getirisini tahmin } \\
\text { edebilmektedir. }\end{array}$ \\
\hline $\begin{array}{l}\text { Canbaş vd. } \\
\text { (1997) }\end{array}$ & 1993:1997 & & $\begin{array}{l}\text { Hisse Senedi Getirisi, Finansal } \\
\text { Oranlar }\end{array}$ & $\begin{array}{l}\text { Hisse senedi getirisini, } \mathrm{F} / \mathrm{K} \text { oranı, } \\
\mathrm{PD} / \mathrm{DD} \text {, ile likidite, karlıı ve } \\
\text { sermaye yapısı oranları etkilemekte } \\
\text { olduğunu tespit etmişlerdir. }\end{array}$ \\
\hline $\begin{array}{l}\text { Batchelor ve } \\
\text { Orakcıoğlu } \\
\text { (2003) }\end{array}$ & $\begin{array}{l}\text { 1990-1994 } \\
\text { Günlük }\end{array}$ & GARCH & $\begin{array}{l}\text { Hisse ve Nakit Temettü, Hisse } \\
\text { senedi Fiyatı }\end{array}$ & $\begin{array}{l}\text { Nakit temettü açıklamasının fiyat } \\
\text { üzerine etkisi bulunamamışı̧ı. }\end{array}$ \\
\hline $\begin{array}{l}\text { Omran ve } \\
\text { Ragab (2004) }\end{array}$ & $1996-2000$ & $\begin{array}{l}\text { Doğrusal ve } \\
\text { Doğrusal } \\
\text { Olmayan } \\
\text { Regresyon }\end{array}$ & $\begin{array}{l}\text { Finansal oranlar (10 Adet), } \\
\text { Hisse Senedi Getirisi }\end{array}$ & $\begin{array}{l}\text { Finansal oranlarla hisse senedi } \\
\text { getirisi arasında doğrusal olmayan } \\
\text { bir iliş̧ki tespit edilmiştir. }\end{array}$ \\
\hline $\begin{array}{l}\text { Şamiloğlu } \\
(2005)\end{array}$ & $\begin{array}{l}1999,2000 \\
2001,2002 \\
\text { ve } \\
1999-2002\end{array}$ & $\begin{array}{l}\text { Çoklu } \\
\text { Regresyon } \\
\text { Analizi }\end{array}$ & $\begin{array}{l}\text { Hisse başına getiri (HBG), Hisse } \\
\text { fiyatı (HK), Faaliyet Kazancı } \\
\text { (FK), Hisse başına kazanç } \\
\text { (HBK), Hisse başına defter } \\
\text { değeri (HBDD), Yıllık büyüme } \\
\text { (YB) }\end{array}$ & $\begin{array}{l}\text { HK ile HBK ve HBDD arasında } \\
\text { anlamlı bir ilişki vardır. }\end{array}$ \\
\hline Oh vd. (2006) & $\begin{array}{l}1981-2000 \\
\text { Yıllık }\end{array}$ & $\begin{array}{l}\text { Panel Veri } \\
\text { Analizi }\end{array}$ & $\begin{array}{l}\text { Hisse Senedi Fiyatı, Hisse } \\
\text { Başına Kazanç }\end{array}$ & $\begin{array}{l}\text { Hisse fiyatları uzun dönemde ve } \\
\text { ortalamada firma temelleri ile } \\
\text { hareket ettiği gözlenmiştir. }\end{array}$ \\
\hline $\begin{array}{l}\text { Ege ve } \\
\text { Bayrakdaroğlu } \\
\text { (2007) }\end{array}$ & $\begin{array}{l}2004 \\
\text { Aylık }\end{array}$ & $\begin{array}{l}\text { Loistik } \\
\text { Regresyon }\end{array}$ & $\begin{array}{l}\text { Likidite oranları (CO, LO, NO), } \\
\text { Faaliyet oranları (ADH, SDH, } \\
\text { DVDH, TVDH, ÖZDH), } \\
\text { Karlılık oranları (AK, BKMINKM, } \\
\text { EFKM, VOKO), } \\
\text { Finansal yapı oranları (OSAT, } \\
\text { TBTA, KVBTB, DSP, UVNTB) } \\
\text {,Borsa performans oranları } \\
\text { (F/K) }\end{array}$ & $\begin{array}{l}\text { Finansal oranlar belirlenerek, düşük } \\
\text { ve yüksek getirili şirketler tespit } \\
\text { edilmiştir. }\end{array}$ \\
\hline $\begin{array}{l}\text { Dehuan ve Jin } \\
(2008)\end{array}$ & Yillık & $\begin{array}{l}\text { Basit ve } \\
\text { Çoklu } \\
\text { Regresyon }\end{array}$ & $\begin{array}{l}\text { Hisse senedi getirisi, Toplam } \\
\text { varlık Devir Hızı, Hisse Başına } \\
\text { Kardaki Değişim, Kar Marjı, } \\
\text { Aktif Karlıı̆ı̆, Özsermaye } \\
\text { Karlıı̆ığı Satışlardaki Karlııı }\end{array}$ & $\begin{array}{l}\text { Bağımsız değişkenlerin açıklanan } \\
\text { dönemin sadece ilk iki döneminde } \\
\text { Hisse senedi getirisini etkilediğini } \\
\text { tespit etmişlerdir. }\end{array}$ \\
\hline $\begin{array}{l}\text { Moderes vd. } \\
(2008)\end{array}$ & $\begin{array}{l}\text { 2001-2005 } \\
\text { Aylık }\end{array}$ & & Aşırı Getiri, Finansal Oranlar & $\begin{array}{l}\text { Aktif Karlıı̆ı, Kar Marjı, Fiyat / } \\
\text { kazanç oranı ile Aşırı Getiri arasında } \\
\text { anlamlı ilişki olduğu gözlenmiştir. }\end{array}$ \\
\hline Horasan (2009) & $\begin{array}{l}2000-2006 \\
\text { Yıllık }\end{array}$ & $\begin{array}{l}\text { Regresyon } \\
\text { Analizi }\end{array}$ & $\begin{array}{l}\text { Fiyat / Kazanç Oranı , } \\
\text { Gecikmeli Getiri, Kapanış Fiyatı }\end{array}$ & $\begin{array}{l}\text { Fiyat / Kazanç oranı ile kapanış } \\
\text { fiyatları arasında anlamlı pozifif } \\
\text { ilişki, gecikmeli getiri ile anlamlı } \\
\text { negatif ilişki tespit edilmiştir. }\end{array}$ \\
\hline $\begin{array}{l}\text { Günalp } \\
\text { vd.(2010) }\end{array}$ & 2003-2007 & $\begin{array}{l}\text { Regresyon } \\
\text { Analizi }\end{array}$ & $\begin{array}{l}\text { Nakit Temettü Açıklaması, } \\
\text { Hisse Senedi Getirisi }\end{array}$ & $\begin{array}{l}\text { Nakit Temettünün açılkanması } \\
\text { sonrasında hisse başına nakit } \\
\text { temettü oranı ile kümülatif } \\
\text { normalüstü getiri arasında anlamlı } \\
\text { negatif bir iliş̧ki tespit edilmiştir. }\end{array}$ \\
\hline $\begin{array}{l}\text { Okafor vd. } \\
(2011)\end{array}$ & 1998-2005 & $\begin{array}{l}\text { Çoklu } \\
\text { Regresyon }\end{array}$ & $\begin{array}{l}\text { Hisse Senedi Fiyat Riski, Kar } \\
\text { Patı Dağıtımı }\end{array}$ & $\begin{array}{l}\text { Kar Payı Tolamı, Hisse fiyat Riski } \\
\text { üzerine negatif, kar payı dağıtım } \\
\text { oranı bazı yıllarda negatif, bazı } \\
\text { yıllarda ise pozitif etkiye sahip } \\
\text { olduğu gözlenmiştir. }\end{array}$ \\
\hline
\end{tabular}




\begin{tabular}{|l|l|l|l|l|}
\hline Khan vd. (2011) & $\begin{array}{l}\text { 2001-2010 } \\
\text { Yıllık }\end{array}$ & $\begin{array}{l}\text { Toplam Kar Payı, Hisse Başına } \\
\text { Panel Veri } \\
\text { Analizi }\end{array}$ & $\begin{array}{l}\text { Kazanç, Özsermaye Karlılığı, } \\
\text { Vergi Sonrası Kar, Hisse Senedi } \\
\text { Fiyatı }\end{array}$ & $\begin{array}{l}\text { Sayılan değişkenler ile Hisse senedi } \\
\text { fiyatı arasında pozitif ilişki tespit } \\
\text { edilmiştir. }\end{array}$ \\
\hline Habib (2012) & - & $\begin{array}{l}\text { Korelasyon } \\
\text { Analizi, } \\
\text { Regresyon } \\
\text { Analizi }\end{array}$ & $\begin{array}{l}\text { Kar Payı Getirisi, Kar Payı } \\
\text { Ödeme Oranı, Hisse Fiyatı }\end{array}$ & $\begin{array}{l}\text { Kar payı getirisi ile hisse fiyatı } \\
\text { pozitif; kar payı ödeme oranı ile } \\
\text { negatif ilişkilidir. }\end{array}$ \\
\hline
\end{tabular}

\section{VERI SETI VE YÖNTEM}

İstanbul Menkul Kıymetler Borsası IMKB 30 endeksi kapsamında yer alan 16 şirket için 1998-2010 dönemine ait 10 değişken kullanılmıştır. Kullanılan değişkenler Tablo 2'de gösterilmiştir.

Burada 1998-2010 arasındaki günlük verilerden Aralık ayının son işlem gününde hisse senedinin aldığı değer, hisse senedinin yılsonu kapanış fiyatı olarak belirlenmiştir. Hisse senetlerinin yılsonu kapanış değerleri www.ibsyazilim.com sitesinden temin edilmiştir. Çalışmada iki model üzerinde durulmuştur ve modeller şu şekildedir:

Tablo 2: Çalışmada Kullanılan Bağımlı ve Bağımsız Değişkenler

\begin{tabular}{|c|c|c|}
\hline \multicolumn{2}{|c|}{ DEĞIŞKENLER } & AÇIKLAMA \\
\hline \multirow{2}{*}{$\begin{array}{l}\overline{\bar{\varepsilon}} \\
\text {, } \\
\bar{D}\end{array}$} & CLS & Hisse Kapanış Fiyatı \\
\hline & RSR & Hisse Getiri Oranı \\
\hline \multirow{8}{*}{$\begin{array}{l}\frac{N}{\bar{N}} \\
\underline{\bar{N}} \\
\text {, } \\
\infty\end{array}$} & DPR & Temettü Ödeme Oranı \\
\hline & ROA & Aktif Karlılığı \\
\hline & P_E & Fiyat Kazanç Oranı \\
\hline & EPS & Hisse Başına Kar \\
\hline & NPI & Net Kar Büyümesi \\
\hline & M_B & Piyasa Değeri Defter Değeri Oranı \\
\hline & MVI & Piyasa Değeri Artışı \\
\hline & ROE & Özsermaye Karlılığı \\
\hline
\end{tabular}

Model 1:

$C L S=\beta_{1}+\beta_{2} D P R+\beta_{3} E P S+\beta_{4} R O A+\beta_{5} N P I+\beta_{6} M B+\beta_{7} M V I+\varepsilon_{i}$
Model 2:

$\mathrm{RSR}=\beta_{1}+\beta_{2} \mathrm{MVI}+\beta_{3} \mathrm{EPS}+\beta_{4} \mathrm{ROA}+\varepsilon_{\mathrm{i}}$

Çalışmaya dâhil edilen IMKB 30 Endeksi içerisinde yer alan hisseler isimleri ve kodları aşağıda Tablo3'te verilmiştir.

Panel veri aynı yatay kesit birimlerinin (firma, hanehalkı, şehir, bölge vb.) zaman içerisinde tekrarlı gözlemlerinden oluşan veri seti olarak tanımlanmaktadır. Dolayısıyla panel verilerde, hem yatay kesit ve hem de zaman boyutu söz konusudur. (Nargelecekenler, 2011:168) Diğer bir ifadeyle panel veri, kesit analizi ile zaman serisi analizini birleştirmektedir.

Bütün zaman serileri analizinde olduğu gibi, hem zaman hem de yatay kesit analizini bir arada gerçekleştiren panel veri analizlerinde de değişkenler arasında sahte ilişkilere neden olunmaması için değişkenlerin durağan olması gerekmektedir (Korkmaz,2010:100). Durağanlık, birim kök testi ile araştırılır. Panel birim kök testleri de iki guruba ayrılmaktadır. Birinci kuşak testler, birimler arasında korelasyon olmadığını varsaymaktadır. Korelasyon varsa bu testlerin gücü zayıftır. İkinci kuşak panel birim kök testlerinin temel özelliği ise, birimlere ait seriler arasında korelasyon olduğunu varsaymaktadır (Tatoğlu,2012:199). Tablo 4'te en çok kullanılan panel birim kök testleri verilmiştir.

Yatay kesit bağımlılığını test etmede kullanılan ikinci nesil birim kök testlerinden en çok kullanılan Pesaran (2004) testi,

$$
C D=\sqrt{\frac{2 T}{N(N-1}} \sum_{i=1}^{N-1} \sum_{j=i+1}^{N} \hat{p}_{i j}
$$

Tablo 3: Kullanılan Hisse Senetleri ve Kodları

\begin{tabular}{|l|c|l|l|}
\hline \multicolumn{1}{|c|}{ HISSE ADI } & HISSE KODU & \multicolumn{1}{c|}{ HISSE ADI } & \multicolumn{1}{c|}{ HISSE KODU } \\
\hline Akbank & AKBNK & Petkim Petrokimya Holding & PETKM \\
\hline Arçelik & ARCLK & OMV Petrol Ofisi & PTOFS \\
\hline Doğan Holding & DOHOL & Türk Şişe Cam Fabrikaları & SISE \\
\hline Ereğli Demir Çelik & EREGL & Türk Hava Yolları & THYAO \\
\hline Finansbank & FINBN & Tofaş Oto Fabrikaları & TOASO \\
\hline Garanti Bankası & GARAN & Türk Sanayi Kalkınma Bankası & TSKB \\
\hline Hürriyet Gazetecilik & HURGZ & Türkiye Petrol Rafineleri & TUPRS \\
\hline Koç Holding & KCHOL & Yapı Kredi Bankası & YKBNK \\
\hline
\end{tabular}


Tablo 4: Panel Birim Kök Testleri

\begin{tabular}{|l|l|}
\hline Birinci Nesil Birim Kök Testleri & İkinci Nesil Birim Kök Testleri \\
\hline Levin, Lin and Chu (2002) & Bai and Ng (2004) \\
\hline Breitung (2000) & Moon and Perron (2004) \\
\hline Im, Peasaran and Shin (2003) & Philips and Sul (2003) \\
\hline Fisher ADF (Maddala and Wu,1999) & Pesaran (2004) \\
\hline Fisher Philips and Perron (Choi,2001) & Choi (2002) \\
\hline Hadri (2000) & Chang (2002,2004) \\
\hline
\end{tabular}

( Not: Bu tablo yazarlar tarafından oluşturulmuştur.)

şeklinde hesaplanır ve yaklaşık olarak $\mathrm{N}(0,1)$ dağılım sergiler. (Nargele çekenler,2011:171)

Birinci nesil birim kök testlerinden Im, Pesaran ve Shin (IPS) testi, verileri birleştirmek yerine tüm birimler için zaman serilerine ayrı ayrı birim kök testi uygular. Ayrıca IPS testi, tüm bireysel ADF test istatistiklerinin bir ortalamasıdır (Tatoğlu,2012:212).

$$
\bar{t}=\frac{1}{N} \sum_{L=1}^{N} t_{p_{i}}
$$

Birinci nesil birim kök testlerinden Fisher ADF ve Fisher Philips ve Perron Panel Birim Kök Testlerinde, veri setinin dengeli panel olması şartı yoktur ve bireysel seriler boşluklara sahip olabilmektedir. Bu özellik diğer testlere göre, esneklik sağlayıp Fisher ADF ve Fisher PP test istatistikleri sırasıyla

$$
\begin{aligned}
& \lambda=-2 \sum_{i=1}^{N} \ln \left(p_{i}\right) \quad \rightarrow X_{2 N}^{2} \\
& \text { ve, } \\
& Z=\frac{1}{2 \sqrt{N}} \sum_{i=1}^{N}\left(-2 \ln \left(p_{i}\right)-2\right) \rightarrow N(0,1)
\end{aligned}
$$

şeklinde hesaplanır. Burada, $p_{i^{\prime}}$ yatay kesit i için birim kök testinin olasılık değeridir (Tatoğlu,2012:215).

Panel veri modellerinde bireysel etkiler ve zaman etkilerin, rassal ya da sabit olabildiği konusunda bu etkilerden hangisinin seçileceği hususunda BreuschPagan Lagrange Multiplier (LM) testinden faydalanılır. LM (1980) testi bireysel ve zaman etkileri olmadığı hipotezini test etmektedir. Panel veri modellerinde, içsellik sorunun olup olmadığı belirlenmelidir. Bu da panel veri modellerinde tahminler arasında seçim yapmak amacıyla kullanılan ve tanımlama hatasını sınamak için geliştirilen Hausman spesifikasyon testi ile mümkündür. Hausman testi, bireysel etkilerle hata teriminin ilişkisiz olduğu hipotezini test eder. $\mathrm{H}_{0}$ hipotezi reddedildiğinde sabit etkiler modeli tercih edilirken, $\mathrm{H}_{0}$ kabul edildiğinde ise rassal etkiler modeli kullanılmaktadır. Sıfır hipotezinin kabul edilmesi halinde hem genelleştirilmiş en küçük kareler tahmincisi hem de grup içi (within) tahmincisi tutarlı sonuçlar verirken, sıfır hipotezinin reddedilmesi halinde grup içi tahmincisi tutarlı olacaktır sonucuna varılır. (Güvenek, Alptekin,2010:183).

\section{BULGULAR}

Çalışmada ele alınan 16 şirketin hisse senedi kapanış fiyatları ve hisse getiri oranı ile nakit kar payı dağıtım oranı, aktif karlılığı, fiyat/kazanç oranı, hisse başına kar, net kar büyümesi, piyasa değeri/defter değeri, piyasa değeri ve öz sermaye karlılığı değişkenleri arasındaki ilişki incelenmiştir Serilere ait tanımlayıc istatistikler Tablo 5'te sunulurken, serilere ait korelasyon matrisi değerleri de Tablo 6'da gösterilmiştir.

Tablo 5 incelendiğinde Jarque-Bera olasılık değerlerine bakıldığında serilere ait hata terimlerinin normal dağılmadığı hipotezinin reddedildiği görülmüştür. Buna göre normal dağılım varsayımının sağlandığı söylenebilmektedir.

Tablo 6'dan elde edilen korelasyon matrisi sonuçlarına göre (P_E) Fiyat Kazanç Oranı ile (CLS) hisse senedi kapanış fiyatları, (DPR) Temettü dağıtım oranı,

Tablo 5: Serilere Ait Tanımlayıcı İstatistikler

\begin{tabular}{|l|c|c|c|c|c|c|c|c|c|c|}
\hline & CLS & DPR & ROA & P_E & EPS & NPI & M_B & MVI & ROE & RSR \\
\hline Ortalama & 2.6073 & 0.1755 & 4.5382 & 26.283 & 0.6743 & 39.654 & 2.5254 & 0.6526 & 12.606 & 0.1515 \\
\hline Medyan & 1.5660 & 0.0000 & 3.8170 & 11.346 & 0.4710 & 25.141 & 1.5390 & 0.2920 & 15.319 & 0.0090 \\
\hline Maksimum & 36.096 & 1.3410 & 31.811 & 602.78 & 8.1360 & 7572.7 & 35.425 & 11.115 & 63.469 & 3.5890 \\
\hline Minimum & 0.0220 & 0.0000 & -25.214 & 0.8790 & -5.1570 & -7590.0 & 0.2590 & -0.8060 & -178.63 & -0.8890 \\
\hline Std. Sapma & 3.9232 & 0.2836 & 7.2595 & 62.988 & 1.3154 & 1002.7 & 3.6987 & 1.5801 & 25.502 & 0.8121 \\
\hline Jarque-Bera & 10386.4 & 109.95 & 185.11 & 21503.7 & 1267.5 & 11220.0 & 12541.2 & 1728.3 & 3936.1 & 213.66 \\
\hline Olasıllık değeri & 0.0000 & 0.0000 & 0.0000 & 0.0000 & 0.0000 & 0.0000 & 0.0000 & 0.0000 & 0.0000 & 0.0000 \\
\hline Gözlem sayısı & 208 & 208 & 208 & 208 & 208 & 208 & 208 & 208 & 208 & 208 \\
\hline
\end{tabular}


(ROA) aktif karlılığı, (EPS) hisse başına kar, (NPI) net kar büyümesi ve (ROE) özsermaye karlılığı ile arasındaki ilişkisinin negatif olduğu, (NPI) net kar büyümesi ile (M_B) piyasa değeri defter değeri oranı arasındaki ilişkinin, (DPR) Temettü dağıtım oranı ile (MVI) piyasa değeri artışı arasındaki ilişkinin ve (M_B) piyasa değeri defter değeri oranı ile (ROE) özsermaye karlılığı arasındaki ilişkinin de negatif olduğu gözlemlenmiştir. Diğer değişkenler arasındaki korelasyon ise pozitif yönlüdür.

Panel veri analizi yaparken önemli durumlardan biri analizde kullanılan seriler arasında yatay kesit bağımlıı̆ı̆ olup olmadığıdır. Birimler arası korelasyon olması durumunda birinci nesil birim kök testleri kullanılması hatalı sonuçlar elde edilmesine neden olabilir. Çalışmada kullanılacak modeller için bağımsız değişkenlerin belirlenmesinde Illeriye Doğru Adımsal Ekleme (Forward Stepwise-Wald) yöntemine başvurulmuş ve belirlenen bu modeller için yatay kesit bağımlıı̆̆ı, ikinci nesil birim kök testlerinden olan Pesaran panel birim kök testi (CD) ile araştırılmıştır. Pesaran CD testi sonucuna göre, değişkenlerde yatay kesit bağımlılığının olmadığı sonucuna varılmıştır. Pesaran CD testi sonuçları Tablo 7'de görülmektedir.
Panel analizlerinin yapılabilmesi için kullanılan serilerin, durağan olması oldukça önemlidir. Çünkü eğer bir seri durağan değilse, değişkenler arasında sahte ilişkiler ortaya çıkmaktadır. Model 1 ve Model 2 için ele alınması gereken değişkenlerin durağanlığı, birinci nesil birim kök testleri olan Fisher ADF, Fisher PP ve IPS testleri ile araştırılmıştır. Öncelikle serilerin düzeyde durağanlıkları araştırılmış ve elde edilen bulgular Tablo 8'de gösterilmiştir.

Tablo 7: Pesaran CD Testi Sonuçları

\begin{tabular}{|c|c|c|c|}
\hline \multicolumn{2}{|c|}{ Model 1 } & \multicolumn{2}{c|}{ Model 2 } \\
\hline $\mathrm{CD}$ & Olasılık Değeri & $\mathrm{CD}$ & Olasılık Değeri \\
\hline 16.254 & 0.0000 & 8.604 & 0.000 \\
\hline
\end{tabular}

Tablo 8'den elde edilen ampirik sonuçlar, bütün değişkenler için $\mathrm{H}_{0}$ hipotezinin reddedildiğini yani $\% 5$ seviyesinde bütün serilerin düzey değerlerinde durağan olduğunu göstermektedir.

Durağanlığın araştırılmasından sonra çalışmanın bu kısmında, bireysel etkilerin ve zaman etkisinin rassal veya sabit olduğunu belirlemek amacıyla Breusch Pagan Lagrange Multiplier (LM) testinden faydalanıl-

Tablo 6: Serilere Ait Korelasyon Matrisi Sonuçları

\begin{tabular}{|c|c|c|c|c|c|c|c|c|c|c|}
\hline & CLS & DPR & ROA & P_E & EPS & NPI & M_B & MVI & ROE & RSR \\
\hline CLS & 1.00000 & 0.50685 & 0.12849 & -0.07529 & 0.32179 & 0.04369 & 0.00414 & $3.61 \mathrm{E}-05$ & 0.10243 & 0.15032 \\
\hline RSR & 0.15032 & 0.01120 & 0.06463 & 0.04179 & 0.14201 & 0.10373 & 0.35621 & 0.69082 & 0.01818 & 1.00000 \\
\hline DPR & 0.50685 & 1.00000 & 0.40389 & -0.11984 & 0.44436 & 0.12932 & 0.07017 & -0.02461 & 0.25670 & 0.01120 \\
\hline ROA & 0.12849 & 0.40389 & 1.00000 & -0.13769 & 0.62295 & 0.26365 & 0.06012 & 0.06894 & 0.72715 & 0.06463 \\
\hline P_E & -0.07529 & -0.11984 & -0.13769 & 1.00000 & -0.15581 & -0.07524 & 0.13257 & 0.02658 & -0.14038 & 0.04179 \\
\hline EPS & 0.32179 & 0.44436 & 0.62295 & -0.15581 & 1.00000 & 0.34197 & 0.03473 & 0.04455 & 0.55741 & 0.14201 \\
\hline NPI & 0.04369 & 0.12932 & 0.26365 & -0.07524 & 0.34197 & 1.00000 & -0.06094 & 0.07661 & 0.35844 & 0.10373 \\
\hline M_B & 0.00414 & 0.07017 & 0.06012 & 0.13257 & 0.03473 & -0.06094 & 1.00000 & 0.47952 & -0.16598 & 0.35621 \\
\hline MVI & $3.61 E-05$ & -0.02461 & 0.06894 & 0.02658 & 0.04455 & 0.07661 & 0.47952 & 1.00000 & 0.00254 & 0.69082 \\
\hline ROE & 0.10243 & 0.25670 & 0.72715 & -0.14038 & 0.55741 & 0.35844 & -0.16598 & 0.00254 & 1.00000 & 0.01818 \\
\hline
\end{tabular}

Tablo 8: Serilere Ait Durağanlığının Düzeyde I(0) Araştırılması

\begin{tabular}{|c|c|c|c|c|c|c|c|c|}
\hline & \multicolumn{2}{|c|}{ CLS } & \multicolumn{2}{|c|}{ DPR } & \multicolumn{2}{|c|}{$\mathrm{ROA}$} & \multicolumn{2}{|c|}{ M_B } \\
\hline Method & $\begin{array}{l}\text { İstatistik } \\
\text { Değeri }\end{array}$ & $\begin{array}{l}\text { Olasılık } \\
\text { Değeri }\end{array}$ & $\begin{array}{l}\text { İstatistik } \\
\text { Değeri }\end{array}$ & $\begin{array}{l}\text { Olasılık } \\
\text { Değeri }\end{array}$ & $\begin{array}{l}\text { İstatistik } \\
\text { Değeri }\end{array}$ & $\begin{array}{l}\text { Olasılık } \\
\text { Değeri }\end{array}$ & $\begin{array}{l}\text { İstatistik } \\
\text { Değeri }\end{array}$ & $\begin{array}{l}\text { Olasılık } \\
\text { Değeri }\end{array}$ \\
\hline $\begin{array}{l}\text { Im, Pesaran ve Shin W } \\
\text { İstatistiği }\end{array}$ & -3.68734 & 0.0001 & -4.80068 & 0.0000 & -5.57783 & 0.0000 & -13.5739 & 0.0000 \\
\hline ADF - Fisher $X^{2}$ & 67.0008 & 0.0003 & 70.3800 & 0.0003 & 77.2365 & 0.0000 & 134.709 & 0.0000 \\
\hline \multirow[t]{2}{*}{ PP - Fisher $X^{2}$} & 47.2323 & 0.0404 & 79.2888 & 0.0000 & 79.6114 & 0.0000 & 101.670 & 0.0000 \\
\hline & \multicolumn{2}{|c|}{ EPS } & \multicolumn{2}{|c|}{ NPI } & \multicolumn{2}{|c|}{ MVI } & \multicolumn{2}{|c|}{ RSR } \\
\hline Method & $\begin{array}{c}\text { İstatistik } \\
\text { Değeri }\end{array}$ & $\begin{array}{l}\text { Olasılık } \\
\text { Değeri }\end{array}$ & $\begin{array}{l}\text { İstatistik } \\
\text { Değeri }\end{array}$ & $\begin{array}{l}\text { Olasılık } \\
\text { Değeri }\end{array}$ & $\begin{array}{l}\text { İstatistik } \\
\text { Değeri }\end{array}$ & $\begin{array}{l}\text { Olasılık } \\
\text { Değeri }\end{array}$ & $\begin{array}{l}\text { İstatistik } \\
\text { Değeri }\end{array}$ & $\begin{array}{l}\text { Olasılık } \\
\text { Değeri }\end{array}$ \\
\hline $\begin{array}{l}\text { Im, Pesaran ve Shin W } \\
\text { istatistiği }\end{array}$ & -8.35025 & 0.0000 & -10.6429 & 0.0000 & -11.6781 & 0.0000 & -11.2527 & 0.0000 \\
\hline ADF - Fisher $\chi^{2}$ & 102.514 & 0.0003 & 111.339 & 0.0000 & 153.139 & 0.0003 & 149.723 & 0.0000 \\
\hline PP - Fisher $\chi^{2}$ & 134.939 & 0.0000 & 143.092 & 0.0000 & 163.579 & 0.0000 & 190.849 & 0.0000 \\
\hline
\end{tabular}

(Not: Uygun gecikme sayısı, Akaike bilgi kriterine (AIC) göre belirlenmiştir.) 
mıştır. Elde edilen sonuçlar Tablo 9'da gösterilmiştir.

Tablo 9'a genel olarak bakıldığında birim ve zaman etkilerinin varlığı kabul edilmektedir. Bu sonuç$\tan$ hareketle, tahminler iki yönlü rassal etki modeli ile yapılmıştır. Çalışmada, bireysel etkilerle açıklayıcı değişkenler arasında ilişki yani, içsellik problemi olup olmadığı ise Hausman testi ile araştırılmıştır. Buna göre modeller için elde edilen sonuçlar Tablo $10^{\prime}$ da gösterilmiştir.

Tablo 9: Model 1 ve Model 2 için LM testi Sonuçları

\begin{tabular}{|c|c|c|c|c|}
\hline \multicolumn{5}{|c|}{ MODEL 1} \\
\hline Test & $x^{2}$ Değeri & Olasılık Değeri & Hipotez & Karar \\
\hline $\mathrm{LM}_{1}$ & 11.638387 & 0.00064605 & Bireysel etkiler rassal değildir. & Red \\
\hline $\mathrm{LM}_{2}$ & 82.55559 & 0.0000000 & Zaman etkileri rassal değildir. & Red \\
\hline LM & 94.193977 & 0.0000000 & Bireysel etkiler ve zaman etkileri rassal değildir. & Red \\
\hline \multicolumn{5}{|c|}{ 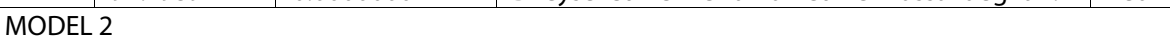 } \\
\hline Test & $x^{2}$ Değeri & Olasılık Değeri & Hipotez & Karar \\
\hline $\mathrm{LM}_{1}$ & 0.66025263 & 0.41647077 & Bireysel etkiler rassal değildir. & Kabul \\
\hline $\mathrm{LM}_{2}$ & 50.485463 & $1.200 \mathrm{E}-12$ & Zaman etkileri rassal değildir. & Red \\
\hline LM & 51.145716 & $7.832 \mathrm{E}-12$ & Bireysel etkiler ve zaman etkileri rassal değildir. & Red \\
\hline
\end{tabular}

Tablo 10: Modeller için Hausman testi Sonuçları

\begin{tabular}{|c|c|c|c|c|}
\hline \multicolumn{5}{|l|}{ MODEL 1} \\
\hline Test & $x^{2}$ Değeri & Olasılık Değeri & Hipotez & Karar \\
\hline Hausman & 7.246675 & 0.2986 & İçsellik problemi yoktur. & Kabul \\
\hline \multicolumn{5}{|l|}{ MODEL 2} \\
\hline Test & $x^{2}$ Değeri & Olasılık Değeri & Hipotez & Karar \\
\hline Hausman & 5.29867 & 0.1512 & İçsellik problemi yoktur. & Kabul \\
\hline
\end{tabular}

Tablo 10'da görüldüğü üzere bu modeller için $\mathrm{H}_{0}$ kabul edildiğinden rassal etkiler modeli kullanılmalıdır. Elde edilen sonuçların LM testi ile de tutarlı olduğu görülmektedir.

Hata terimleri arasında ilişki olması anlamına gelen otokorelasyon, zaman serilerinde olduğu gibi panel veri analizlerinde de önemli bir sorundur. Bu çerçevede ele aldığımız Model 1'de ve Model 2'de otokorelasyon sorununun olup olmadığı araştırılmıştır. Elde edilen sonuçlar Tablo 11'de gösterilmiş ve Model 2'de otokorelasyon yoktur hipotezi kabul edilirken, Model 1'de reddedilmiştir.

Tablo 11:Panel Veri İçin Wooldridge Otokorelasyon Testi Sonucu

\begin{tabular}{|l|l|}
\hline \multicolumn{1}{|c|}{ MODEL 1} & \multicolumn{1}{c|}{ MODEL 2 } \\
\hline $\mathrm{F}(1,15)=356.535$ & $\mathrm{~F}(1,15)=2.005$ \\
\hline Olasılık Değeri: $\quad 0.0000$ & Olasılık Değeri: 0.1772 \\
\hline
\end{tabular}

Modellerde değişen varyans sorunu olup olmadığını araştırmak amacıyla Wald testi yapılmış ve elde edilen sonuçlar Tablo 12'de gösterilmiştir. Buna göre her iki modelde değişen varyans sorunu olduğu görülmüştür.
Tablo 12: Wald Değişen Varyans Testi Sonucu

\begin{tabular}{|l|l|}
\hline \multicolumn{1}{|c|}{ MODEL 1 } & \multicolumn{1}{|c|}{ MODEL 2 } \\
\hline$X^{2}(16)=3930.46$ & $X^{2}(16)=146.90$ \\
\hline Olasılık Değeri: 0.0000 & Olasılık Değeri: 0.0000 \\
\hline
\end{tabular}

Panel veri analizinde, farklı varyans, otokorelasyon veya birimler arası korelasyon sorunlarından en az birinin varlığı modelin tutarsız olacağı anlamına gelir. Bu durumda dirençli standart hatalar elde edilmeli ya da uygun yöntemlerle model tahmini yapılmalıdır. Tablo 11 ve Tablo 12'den görüldüğü üzere, çalışmada ele alınan modellerde otokorelasyon ve farklı varyans sorunu mevcuttur. Hem değişen varyans hem otokorelasyon probleminin var olduğu Model 1 için White cross-section düzeltmesi, sadece değişen varyans sorunu olan Model 2 için ise White diagonal düzeltmesi yapılmıştır. Bu düzeltmeler yapıldıktan sonra iki yönlü rassal etkiler modellerinin tahmin sonuçları değerlendirilebilir. Bu çerçevede yapılmış olan model tahminleri Tablo 13 ve Tablo 14'de gösterilmiştir. 
Tablo 13: Model 1 İçin İki Yönlü Rassal Etkiler Modeli

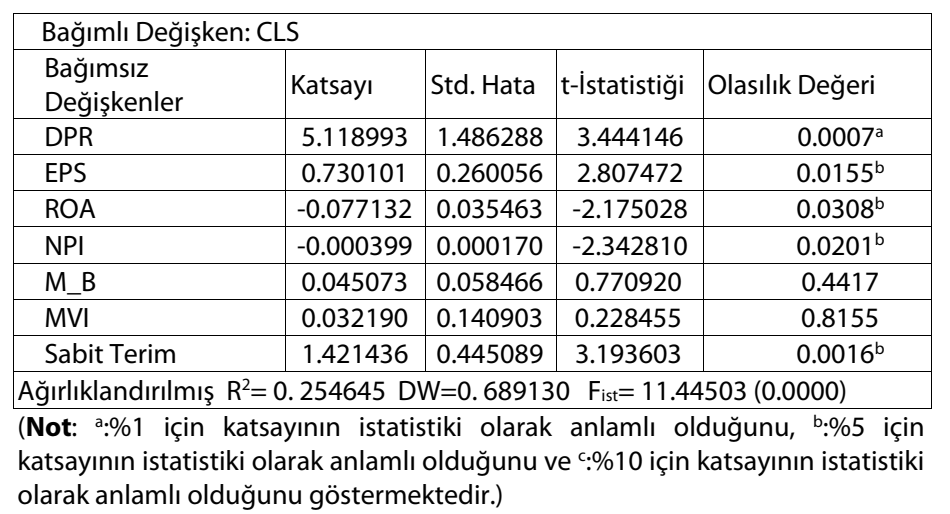

Tablo 14: Model 2 iç̧in İki Yönlü Rassal Etkiler Modeli

\begin{tabular}{|l|c|c|c|c|}
\hline \multicolumn{4}{|l|}{ Bağımlı Değişken: RSR } \\
\hline $\begin{array}{l}\text { Bağımsız } \\
\text { Değişkenler }\end{array}$ & Katsayı & Std. Hata & t-i̇statistiği & Olasılık Değeri \\
\hline MVI & 0.278099 & 0.106597 & 2.608888 & $0.0198^{\mathrm{b}}$ \\
\hline EPS & 0.090306 & 0.026599 & 3.395101 & $0.0008^{\mathrm{a}}$ \\
\hline ROA & -0.003730 & 0.007327 & -0.509104 & 0.6112 \\
\hline Sabit Terim & -0.072176 & 0.065422 & -1.103240 & 0.2712 \\
\hline Ağırlıklandırımış $\mathrm{R}^{2}=0.258442 \mathrm{DW}=2.355307$ & $\mathrm{~F}_{\text {ist }}=23.69885$ & $(0.0000)$ \\
\hline
\end{tabular}

(Not: a:\%1 için katsayının istatistiki olarak anlamlı olduğunu, b:\%5 için katsayının istatistiki olarak anlamlı olduğunu ve c:\%10 için katsayının istatistiki olarak anlamlı olduğunu göstermektedir.)

Tablo 13'ten görüldüğü üzere, temettü ödeme oranındaki (DPR) ve Hisse Başına Kardaki (EPS) değişim, Hisse Senedi Kapanış Fiyatlarını (CLS) artırırken, Aktif Karlılığındaki (ROA) değişim Hisse Kapanış Fiyatlarını (CLS) azaltmaktadır. Net Kar Büyümesi (NPI), Hisse Senedi Fiyatlarını (CLS) negatif etkilemektedir. Piyasa Değeri Defter Değeri (M_B) ve Piyasa Değeri Artışı (MVI), Hisse Senedi Kapanış Fiyatlarını (CLS) etkilememektedir.

Tablo 14'te görüldüğü üzere, Piyasa Değeri Artışı (MVI) ve Hisse Başına Kar (EPS), Hisse Getiri Oranını (RSR) artırırken, Aktif Karlılığı (ROA) ise Hisse Getiri Oranını (RSR) etkilememektedir.

\section{SONUÇ}

Çalışmada, IMKB 30 Endeksine dâhil olan 16 şirketin 1998-2010 yıllarını kapsayan hisse senedinin yılsonu kapanış fiyatı ve hisse getiri oranı ile nakit kar payı dağıtım oranı, aktif karlılığı, fiyat/kazanç oranı, hisse başına kar, net kar büyümesi, piyasa değeri / defter değeri, piyasa değeri ve özsermaye karlılığı değişkenleri arasındaki ilişki panel regresyon modeli ile incelenmiştir. Çalışmada 2 Model kurulmuştur.
Model 1'de Hisse Kapanış fiyatı bağımlı değişken olarak belirlenmiştir. Hisse Kapanış Fiyatını (CLS), Temettü Ödeme Oranındaki (DPR) ve Hisse Başına Kardaki (EPS) değişim artırırken, Aktif Karlıığındaki (ROA) değişim ise azaltmaktadır. Piyasa Değeri Defter Değeri (M_B) ve Piyasa Değeri Artışı (MVI) ise Hisse Kapanış Fiyatını (CLS) etkilememektedir.

Model 2'de ise Hisse Getiri Oranı bağımlı değişken olarak belirlenmiş̧ir. Piyasa Değeri Artışı (MVI) ve Hisse Başına Kar (EPS), Hisse Getiri Oranını (RSR) artırırken, Aktif Karlılığı (ROA) ise etkilememektedir. Sonuç olarak, firma performansını ölçmek için kurulan modellerde, incelenen dönemlerde, firma performansını DPR, EPS, ROA, M_B, MVI etkilemektedir. Firmalara yatırım yapan yatırımcılar, bu yatırımlarını yaparken, özellikle Temettü Ödeme oranına (DPR), Hisse Başına Kar (EPS)'a, Aktif Karlılığına (ROA) dikkat etmeleri önerilmektedir. 


\section{KAYNAKLAR}

Aydoğan, K. ve Muradoğlu, G. (1998) “Do Markets Learn From Experience? Price Reaction To Stock Dividends in The Turkish Market" Applied Financial Economics, 8:41-49.

Basu, S.(1977) "Investment Performance of Common Stocks in Relation to Their Price-Earnings Ratios: A Test of The Efficient Market Hypothesis" The Journal of Finance, 32(3):663-682.

Batchelor, R. ve I. Orakcıoğlu (2003) "Event-Related Garch: TheImpact of Stock Dividends in Turkey" Applied Financial Economics, 13(4):295-307.

Breitung, J.(2000) "The Local Power of Some Unit Root Tests for Panel Data” Baltagi. B(ed.) Nonstationary Panels, Panel Cointegration, and Dynamic Panels, Amsterdam, JAI Press.

Breusch, T. ve Pagan, A. (1980) “The Lagrange Multiplier Test and Its Application to Model Specifications in Econometrics" Reviews of Economics Studies, 47:239-253.

Canbaş, S., Düzakın, H. ve Kılıç, S.B., (2002) "Fundamental and Macroeconomic Information for Common Stock Valuation: TheTurkish Case" Yapı Kredi Economic Review, 13(1):55-64.

Choi, I.(2002) "Unit Root Tests for Panel Data" Journal of International Money and Finance, 20:249-72.

Chang, Y. (2002) "Nonlinear IV Unit Root Tests In Panels With Cross-section Dependency" Journal of Econometrics, 110:261-92.

Chang, Y. (2004) "Bootstrap Unit Root Tests in Panels With Cross Sectional Dependency" Journal of Econometrics, 120:263-293.

Crowder, W.J ve Mark E.W. (1998) "Stock Price Effects of Permanent and Transitory Shocks" Economic Inquiry, 36:540-552.

Dehaun, J. ve Jin, Z.(2008) "Firm Performance and Stock Returns: An Empirical Study of the Top Performing Stocks Listed on Shanghai Stock Exchange" Academy of Accounting and Financial Studies Journal, 12(1):79-85.

Ege, İ. ve Bayrakdaroğlu, A. (2009) "An Analysis of the Performance of ISE Companies Stock Yields Using The Logistic Regression Method" ZKU Journal of SocialSciences, 5(10):139-158.

Günalp, B., Kadıŏlu, E ve Kılıc, S. (2010) "Nakit Temettü Bilgisinin Hisse Senedi Getirisi Üzerinde Önemli Bir Etkisi Olup Olmadığının İMKB'de Test Edilmesi" Hacettepe Üniversitesi İktisadi Ve İdari Bilimler Dergisi, 28(2):47-69.
Güvenek, B. ve Alptekin, V. (2010) "Enerji Tüketimi ve Büyüme İlişkisi: OECD Ülkelerine İlişkin Bir Panel Veri Analizi” Enerji, Piyasa ve Düzenleme, 1(2):172-193.

Habib, Y. Zernigah, I.K. ve Muhammad A.K (2012) "Dividend Policy and Share Price Volatility: Evidence from Pakistan" Global Journal Of Management And Business Research, 12(5):78-84.

Hadri, K. (2000) "Testing for Stationarity in Heterogeneous Panel Data” Econometric Journal, 3: 148-161.

Hatiboglu, Z. (1993) Temel İsletme Finansmanı, İstanbul, Yeni İktisadi ve İsletme Yönetim Dizisi No:10.

Im, K., Pesaran, H. ve Shin, Y. (2003) "Testing for Unit Roots in Heterogenous Panels" Journal of Econometrics, 115(1):53-74.

Khan, K.I, Muhammad, A., Arslan, Q., Adeel, N. ve Maryam, I.K (2011) "Can Dividend Decisions Affect The Stock Prices: A Case of Dividend Paying Companies of KSE" International Research Journal Of Finance and Economics, 76:67-74.

Korkmaz, T. (2010) “FVFM'nin İMKB Ulusal 100 Endeksindeki Geçerliliğinin Panel Veri Analizi İle Test Edilmesi” İstanbul Üniversitesi İsletme Fakültesi Dergisi, 30(1):95-105.

Moon, R. ve B. Perron (2004) "Testing For A Unit Root in Panels With Dynamic Factors" Journal of Econometrics, 122: 81-126.

Lewellen. J (2002) "Predicting Returns with Financial Ratios" Social Science Research Network Working Paper Series, No:4371-02.

Levin, A., Lin, C.F. ve Chu, C. (2002) "Unit Root Tests in Panel Data: Asymptotic and Finitesample Properties" Journal of Econometrics, 108:1-24.

Miller, M ve Rock, K. (1985) "Dividend Policy Under Asymetric Information" Journal Of Finance, 11(4):1031-1050.

Miller M.H. ve Modigliani, F. (1961) "Dividend Policy, Growth, and The Valuation of Shares" Journal of Business, 34(4):411-433.

Maddala, G.S. ve Wu, S. (1999) "A Comparative Study of Unit Root Tests with Panel Data and A New Simple Test" Oxford Bulletin of Economics and Statistics, 61:631-652.

Modares, A, Sajjad, A ve Mozhgan M. (2008) "Testing Linear Relationships Between Excess Rate of Return and Financial Ratios" Social Science Research Network Working Paper Series, No:14. 
Mukherji S., Manjeet S.D. ve Yong H.K. (1997) "A Fundamental Analysis of Korean Stock Returns" Financial Analysts Journal, 53(3):75-80.

Nargeleçekenler M. (2011) "Hisse Senedi Fiyatları ve Fiyat/Kazanç Oranı İlişkisi: Panel Verilerle Sektörel Bir Analiz" Business And Economics Research Journal, 2(2):165-184.

Oh K.Y, Kim B ve Kim H. (2006) "An Empirical Study of The Relation Between Stock Price and EPS in Panel Data: Korea Case" Applied Economics, 38:23612368.

Okafor, C.A., Mgbame, C.O ve Mgbame, A.M.C (2011) "Dividend Policy and Share Price Volatility in Nigeria" Jorind, (9)1:202-210.

Omran, M ve Ragab, A. (2004) "Linear Versus Non-Linear Relationships Between Financial Ratios and Stock Returns: Emprical Evidence From Egyptian Firms" Review of Accounting and Finance, 3 (2):84-102.

Pesaran M.H. (2004) "General Diagnostic Tests for Cross Section Dependence in Panels" Cambridge Working Papers in Economics No: 0435.
Phillips, P.C.B. ve Sul, D. (2003) Dynamic Panel Estimation and Homogeneity Testing Under Crosssection Dependence" Econometrics Journal, 6:217259.

Shen, P (2000) "The P/E Ratio and Stock Market Performance" Economic Review-Federal Reserve Bank of Kansas City, 85(4):23-36.

Shen, P (2000) "The P/E Ratio and Stock Market Performance" Economic Review-Federal Reserve Bank of Kansas City, 85(4):23-36.

Şamiloğlu, F. (2005) "Hisse Getirileri ve Fiyatlarıyla, Kazanç ve Nakit Akımları Arasındaki İlişki: Deri ve Gıda Şirketlerinde Ampirik Bir İnceleme" İstanbul Üniversitesi İsletme Fakültesi Dergisi, 26:120-126.

Tatoğlu F.Y. (2012) İleri Panel Veri Analizi, İstanbul, Beta Yayınevi.

Weston, J.F. ve Copeland, T.E (1992) Managerial Finance, International Edition, New York, The Dryden Pres. 
